University for Business and Technology in Kosovo

UBT Knowledge Center

Nov 7th, 4:45 PM - 5:00 PM

\title{
The impact of the content of the television programming upon the politicization of the Kosovo society
}

\author{
Resul Sinani \\ University for Business and Technology, resul.sinani@ubt-uni.net
}

Follow this and additional works at: https://knowledgecenter.ubt-uni.net/conference

Part of the Communication Commons, and the Political Science Commons

\section{Recommended Citation}

Sinani, Resul, "The impact of the content of the television programming upon the politicization of the Kosovo society" (2014). UBT International Conference. 31.

https://knowledgecenter.ubt-uni.net/conference/2014/all-events/31

This Event is brought to you for free and open access by the Publication and Journals at UBT Knowledge Center. It has been accepted for inclusion in UBT International Conference by an authorized administrator of UBT Knowledge Center. For more information, please contact knowledge.center@ubt-uni.net. 


\title{
The impact of the content of the television programming upon the politicization of the Kosovo society
}

\author{
Resul Sinani \\ University for Business and Technology \\ resul.sinani@ubt-uni.net
}

\begin{abstract}
The effect of the media over the society is the object of the studies of the social science of communication since its founding up to today. A lot of scientific theories explore, argues and explain the connections and the effect of the media over the public. The purpose of this paper is to evident and argument the effect that the media, especially the TV programming has on the politicization of the Kosovar society, which is manifested in a large number of conversations that have to do with politics. In order to argument the direct link between the content of the TV programming (as a media) and political conversations among citizens, this writing will present the results of measuring the contents of the four biggest TV stations in Kosovo: RTK, KTV, RTV 21 and Klan Kosova. What was measured is the amount of programs that have political content within a week at the time when the viewing is at its peak, or in what is known as prime time, from 1700 to $2400 \mathrm{~h}$. It also involves an opinion poll of the public which was asked about the influence of the content of TV programs on their daily conversations. The results of programming contents prove a very high percentage of political programs on these four TV stations (RTK 1, KTV, RTV 21 and Klan Kosova), whereas the results of the public polling prove the direct influence of the contents of this programs on the daily conversations.
\end{abstract}

Keywords: Media, effect, Television, politicization, programming content.

\section{Introduction}

This study evidents the connection between the television programming with the polistisation of the Kosovar society. In order to argument this connection there have been two researches done. In the first one the content of programming was measured, meaning the programs with political content were identified, like the news editions, political and economic debates on four main TV stations in the country: RTK 1, KTV, RTV 21 and Klan Kosova. Whereas the second research is an opinion poll of the citizens who spoke about the influence that the programming content has on their daily conversations. The study also presents the theoretical scientific theory which speaks about studying the concept of the media with the audiences.

The results of the presence of the programs with political content show a high percentage of those programs, a percentage which has its direct effect and is reflected in the subjects of everyday conversations of the individuals who took part in the poll.

The investigation of the programming content is limited on the main four TV stations of the country, RTK, KTV, RTV 21 and Klan Kosova. In the aspect of time, the investigation is spread through one week - the week of May 2014, from the 12th to the 19th. Whereas when it comes to the volume of programming the investigation is focused on prime-time, or the time period which is considered as the most important and which achieves the highest viewership, respectively from 17:00 to 24:00. SO the investigation is limited in one week during a 7 hour period, or 49 hours of programming in each television. The public opinion research is limited to 150 respondents In time aspect has expanded within the same week in which the investigation of TV programming was done, meaning from the 12th to the 19th of May 2014. The opinions of 20 to 25 people were taken each day.

The difficulties of this work were different, starting from the fact that there are no previous studies done in this field of study in our country. Also, a difficulty in itself was the technical aspect of measuring the program contents, but this has been made easier and has been done thanks to the cooperation with the media monitoring company PrimeDB, which has an electronic database which is wide and very advanced. The polls done with the citizens, besides the difficulty of not having an institution which produces such data because of the costs connected to making such a poll was limited to a small number of respondents. 
Whereas, when it comes to methodology, although of different nature the two researches are quantitative, one research provides statistical data about the presence of programs with political content taken as a case study while the other gives statistical data about the influence that the programming content has on every day conversations of the people that were polled. After the statistical data, the comparison and interpretation of the data from both researches was done.

The conclusions taken from this study, the results of the two researches as well as their interpretation are in harmony with the previous scientific theories in the field of communication, respectively with the theory of setting the agenda, which sees the media as the definers of the agendas of its consumers, especially the theses of Bernard Cohen, according to which 'the media do not teach us what to think but what should we think'. Also the results of this study argument the perception that the Kosovar society is politicized, where as there is a direct link between this and the high percentage of political programming on the main TV stations in the country and the high percentage of conversations with political content that are consumed by Kosovar citizens during the day.

\section{The impact of the content of the television programming upon the politicization of the Kosovo society}

The studies about the effects and the influence of the media on society have been widely done and the science has created a large number of theories which explain the connection between the media and the audience, respectively society. In the early stages of studying the effects of the media on society an alarm was rang about the direct negative effect that the media might have on the actions of the individuals, while underlining the notion of social imitation (Maigret, 2010, pg. 41-56). According to Maigret, exactly during the notion of criticism Emile Durkheim takes upon himself to do one of the most brilliant studies of the direct influence on newspapers on individual consciousness in the study Suicidie, published in 1897 (chapter 4), while also being supported by statistical elements. For many decades afterwards the effect of the media was judged, and pre-judged starting from the newspapers, to continue with the radio, which has even been attributed a big contribution in helping the Nazis, led by Adolf Hitler in Germany, and ending up with television, which is believed to be following social and individual violence. (Maigret, 2010, pg. 61). Paul Lazarsfeld, who tarts what is being called 'the empirical wave' in the study of the media and their audiences, the theory of limited effects. In his book The People's Choice (1944), Maigre underlines that Lazarsfeld was the first to show that vote is not an individual choice without any consequences or the product of media campaigns orchestrated by the media, but it can be seen as depended of 3 main factors: class, geographical belonging and religion (Lazarsfeld et al. 1948). Whereas while following this field of study, Lazarsfeld together with his student Elihu Katz, bring a deepened theory of the communication flux on two levels or times (Katz, Lazarsfeld,1955), according to which the direct effect is negated.

With the development of political sciences and the specialist studies about the political communication science brings many more theories who attempt to explain the report of the media with the audience. Maxwell Mc Combs and Donald Shaw (1972) bring the theory of setting the agenda (agenda setting theory). In order to fill this theory we are helped by the theses of Bernard Cohen (1963), according to which the media do not tell us what to think but what should we be thinking about.

This study attempts to 0 find the connection between the content of the TV programming and the politicization of the Kosovar society. The research of the contents of TV programming shows a high presence of programs with political content. Whereas the research of the polling conducted with random citizens, who were spending their free time in coffee shops prove a direct link between the contents TV programming and their random conversations.

The measurement of the weekly programs on four main Kosovar TV stations, RTK 1 (The public broadcaster) KTV, RTV 21 and Klan Kosova, shows that from a total of 196 hours of television programs 90 hours, 47 minutes and 12 seconds , or $46.1 \%$ had a political content.

When it comes to individual RTK1, from a total of 49 hours of programs $19 \mathrm{~h} 22$ ' 38 "- or $39.2 \%$ had programs with political content. KTV from a total of 49 hours of programs transmitted 21h 22' 46", or $43.3 \%$ of political content. RTV 21 from a total of 49 hours of programs transmitted 23h 19' 46", or $47.3 \%$ of various programs with political content. Whereas Klan Kosova from a total of 49 hours of 
programs transmitted programs with political content for $26 \mathrm{~h} 42$ ' 02 ", or, when expressed in percentages $53.9 \%$.

According to these results the station which transmitted the most programs with political content was

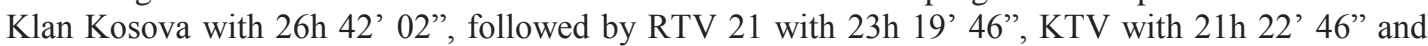
RTK1 with 19h 22' 38"'.

\begin{tabular}{|c|c|c|c|}
\hline TV station & Overall program & $\begin{array}{c}\text { Duration of } \\
\text { programs with } \\
\text { political content }\end{array}$ & $\begin{array}{l}\text { The percentage of } \\
\text { programs with } \\
\text { political content }\end{array}$ \\
\hline RTK 1 & $49 \mathrm{~h}$ & 19h 22' $38^{\prime \prime}$ & $39.2 \%$ \\
\hline KTV & $49 \mathrm{~h}$ & $21 \mathrm{~h} 22^{\prime} 46^{\prime \prime}$ & $43.3 \%$ \\
\hline RTV 21 & $49 \mathrm{~h}$ & 23h 19'46” & $47.3 \%$ \\
\hline Klan Kosova & $49 \mathrm{~h}$ & 26h 42’02” & $53.9 \%$ \\
\hline Overall & $196 \mathrm{~h}$ & 90 h 47' $12 ”$ & $46.1 \%$ \\
\hline
\end{tabular}

Table 1. The duration of television programs with political content on RTK1, KTV, RTV 21 and Klan Kosova. (Source: media monitoring company PrimeDB)

For the needs of this study, with the purpose of argumenting my hypothesis and finding the connection between the contents of the TV programs and the audience, respectively the effect that the television programming content has upon the audiences (citizens), I have conducted a survey with 150 citizens. The age of the respondents was between 22 and 55, giving an average of 39. 82 respondents $(54.66 \%)$ where male whereas, $68(45.33 \%)$ of the respondents were female. The interviews were conducted during the week when the research and the measurements of the television programs were done, so from the 12th up to the 19th of May 2014. 20 to 25 surveys were done every day and the selection of the respondents was random, they were questioned during mid-day when the respondents were on their lunch breaks. Also, restaurants and coffee shops that were selected were those that have a more mature clientele. The young and people of old age were not interviewed, although they may present a special category of studying and two different studies might be done in order to add upon this research. In order to have a fuller understanding of the results of this study what should be done is a poll including over one thousand respondents and this is practically impossible to do by only one researcher, ideally an institute that specializes in public opinion polls should be hired to conduct it. Whatever the case may be, for the needs of this study and taking into consideration that there are no other similar researches that we can refer to, the results of this research are enough to argument and they serve this study enough. For this study we have chosen four of the questions which give enough arguments about the direct link between the television program contents and the contents of the conversations of the daily conversations of the respondents (citizens).

On the question: What were you talking about? - 51.3\% (77 persons), answered that they were talking about politics, which is very high percentage when compared to other alternatives, $14 \%$ (21) answered about work, $24.6 \%$ (37) about family issues and $10.1 \%$ (15) said that they were talking about other subjects (graph. 1). 


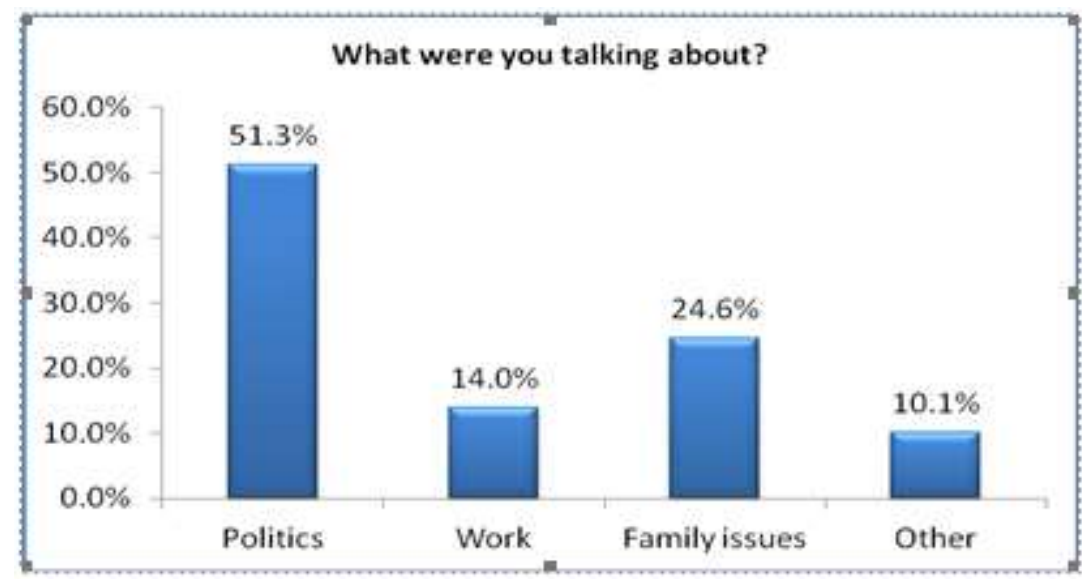

Graph 1. What were you talking about?

The second question that we have chosen for the needs of this study and whose purpose is to show which medium is the one that mostly influences their conversations was this one: Was the subject of your conversation connected with what you have heard/seen/read in the media? The answers prove that that not only the conversations are influenced by the media but that most of them said that Television is the medium which is influencing them the most. $43.3 \%$ ( 65 respondents) answered by television, $2.7 \%$ (4) by radio, $8.0 \%$ (12) by newspapers while $46.0 \%$ (69 people) said that it had nothing to do with the media (graph 2).

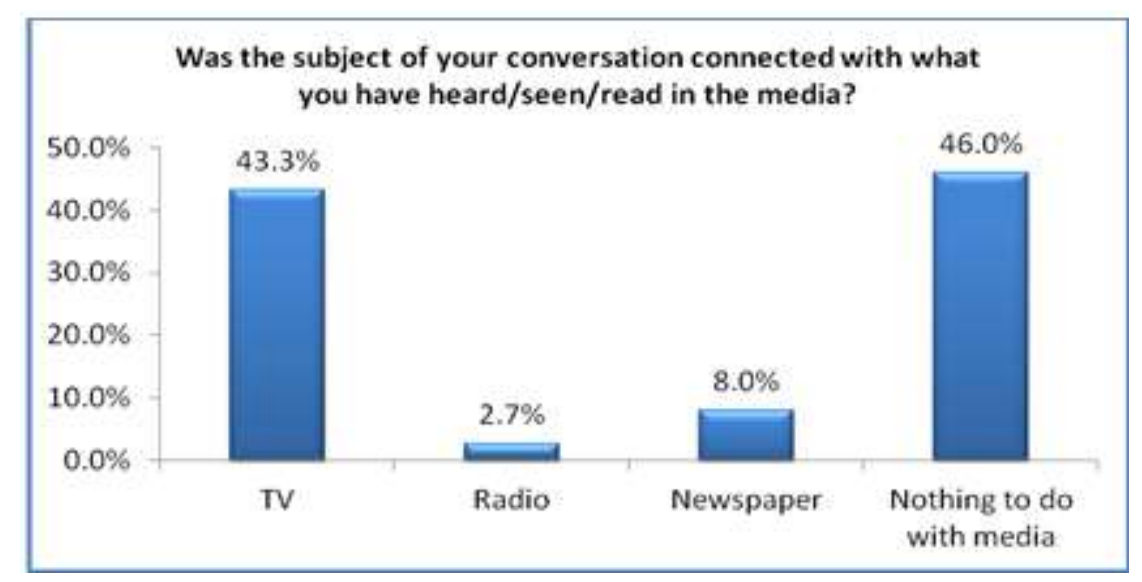

Graph 2. Was the subject of your conversation connected with what you have heard/seen/read in the media?

The third question which we have taken into consideration and which is connected to the subject of this study, is: How often does it happen that, when in company, you talk about the subjects which you $\mathrm{read} / \mathrm{hear} / \mathrm{see}$ in the media? On this question, $59.3 \%$ (89 respondents ) chose the alternative every day, $22.7 \%$ (34) answered often, $15.3 \%$ (23) said rarely, while only $2.4 \%$ (4 respondents) answered that the conversations with their company are never influenced by the media. 


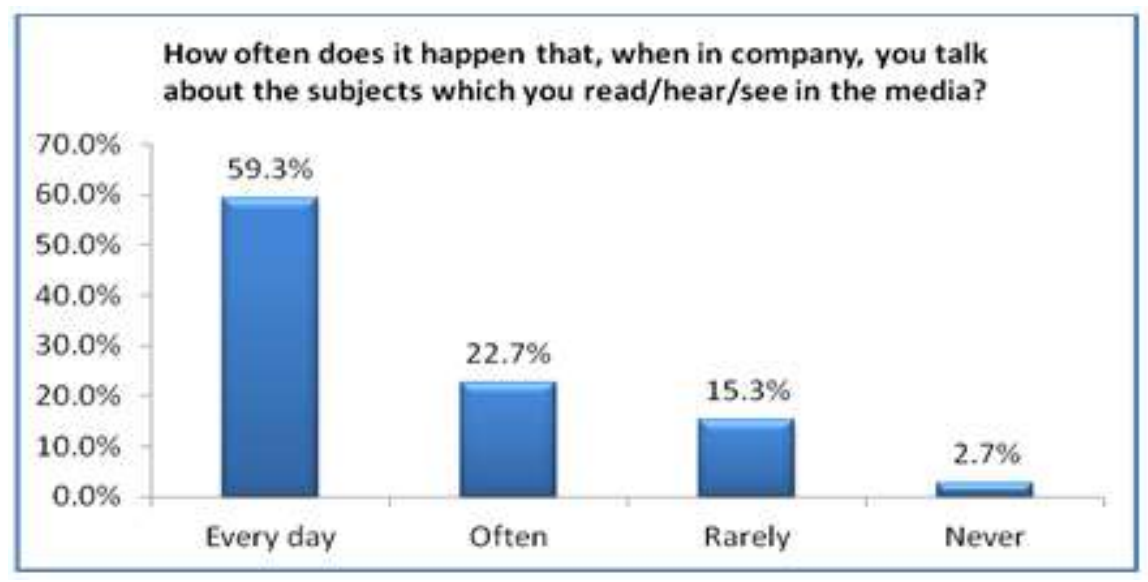

Graph 3. How often does it happen that, when in company, you talk about the subjects which you $\mathrm{read} / \mathrm{hear} / \mathrm{see}$ in the media?

The fourth question, asked in the form: Do you think that television programs influence the conversations you have with the people in whose company you are? - There is an almost complete consensus, where $85.3 \%$ (128 respondents) chose the option Yes, while only $14.7 \%$ (22) chose the No option.

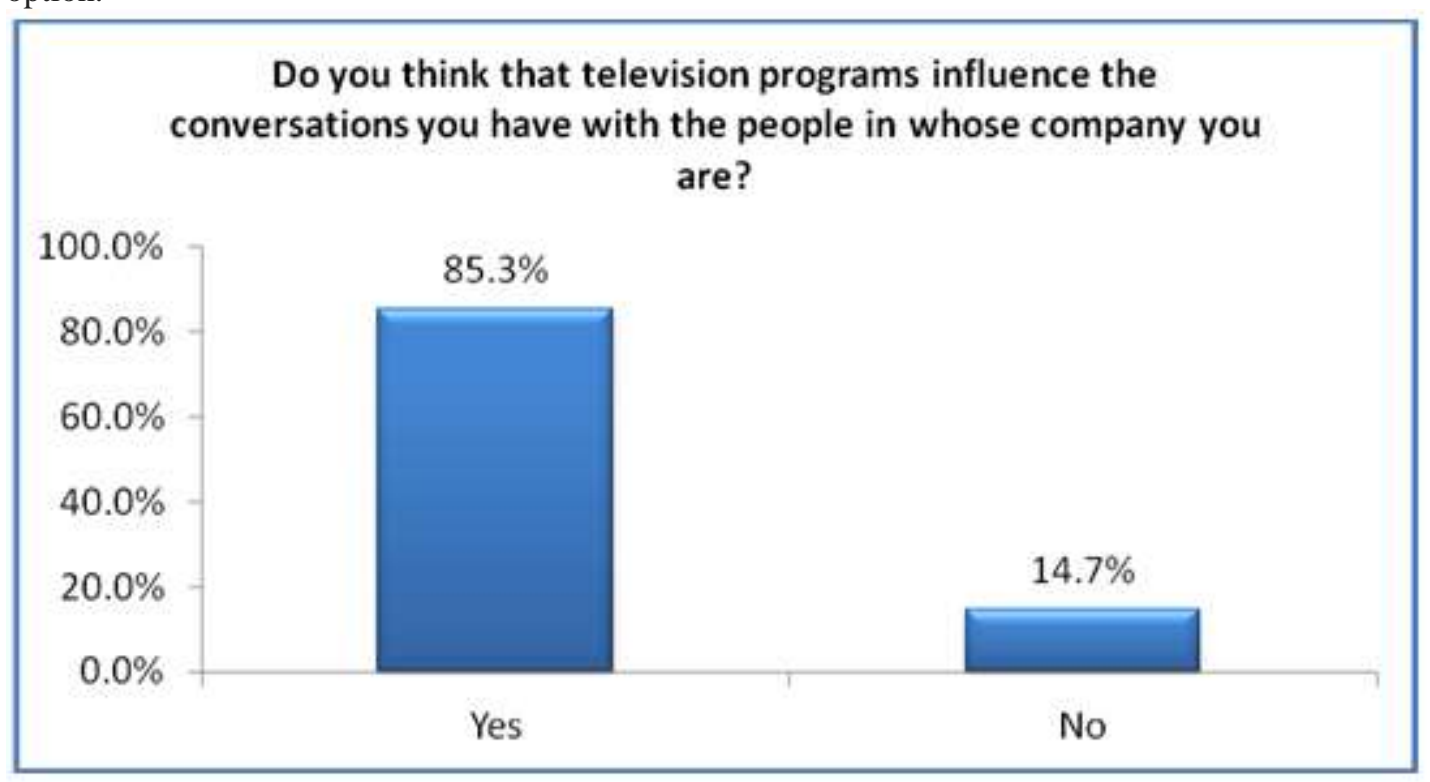

Graph 4. Do you think that television programs influence the conversations you have with the people in whose company you are?

\section{Discussing the results}

The purpose of this study was to evident the high percentage of the transmission of programs with political content and argumenting that e percentage like that has a direct influence on politicizing of Kosovar citizens, although it is not the only reason and the only factor that contributes in such politicization The added factor influencing the politicization is the political situation that our country has been through ring the past decades. There is a well-known fact that the Kosovar population, during 
this period, has had a high interest in news and other programs with political content, solely because within them they found the source of information of utmost interest for their own destiny, but also the destiny of their families, as well as the entire country. This interest should have been fading away with the passing of years, especially after the proclamation of Kosovar independence, but the results of the study show that something like that has not yet happened. Despite the interest that the citizens have about the programs with political content, which is argumented by the results of this study, the purpose was not to research the factors and the causes which have led to this situation. The focus was in argumenting that television, as the medium with most influence in Kosovo and as the main source of information for the citizens has a direct influence on their daily agendas, especially in the content of their conversations, or as we have said earlier to argument the thesis of Cohen that "the media do not tell us what to think, but what should we be thinking about". In this study we have dealt with the first part of his theses, so which is their attitude and what do they think about the subjects which have become a part of their daily conversations, are they for or against them, do they have a positive or a negative approach.

In the previous paragraph we have dealt with the main argument of this study, meaning the effect of the television upon citizens (audience), while in this paragraph we conclude and discuss the presence of a very high percentage of political programs on all four TV stations taken as a case study. IF attention is paid to the programming scheme of these stations, than besides $46.1 \%$ of the programs with political content, about $20 \%$ of the rest of the programs are commercials and promos for various shows, which means that the overall percentage of other types of programs is limited even further. This percentage gets even smaller when we take into consideration that during this time period, so between 17:00 to 24:00 hrs., there is a lot of transmission of foreign programs, like TV series which have a very high prevalence. While the presence of shows with different types of content is extremely limited and almost un-noticeable. Since the reasons why the TV stations are transmitting this level of political programming are not the focus of this study, then we should stay with the fact that, in the stations whose programming we have followed, RTK 1, KTV, RTV 21 and Klan Kosova, during their prime time, scheduling, when the interest of the audiences is the highest and the peak viewership is achieved there is a domination of programs with political content, a fact which is reflected with the audience or the citizens.

Comparing the results of the two researches, the one about the presence of programs with political content on Kosovar national Television channels, gives enough arguments for the hypothesis that a very high percentage of the programming, respectively $46.1 \%$, has political content creates a direct influence on the politicization of the Kosovar society. While when we analyze the second answer, where $43.3 \%$ of the citizens say that their conversations are influenced by radio $2.7 \%$ and newspapers $8.0 \%$, gives almost equal numbers with the answers to the first question, in which $51.3 \%$ of respondents admit that the subject of their conversations is political (compare graph 1 and graph 2).

\section{Conclusion}

This study presents the results of two researches which are used to argument the influence of the contents of TV programming on the politicizing of Kosovar citizens. According to the results of the first research, during the time when the TV viewership is at its peak - prime time - we can see a very high presence of programs with political content in the four main TV stations in the country, RTK 1, KTV, RTV 21 and Klan Kosova. This percentage starts off with 39.2\% with RTK 1 and reaches up to $53.9 \%$ on Klan Kosova, while the overall average of the programs with political content which are transmitted by the four channels that we researched is $46 . \%$. While according to the results of the polls done with the citizens, respectively, according to their answers, the conclusion shows a very high presence of conversations with political content. $51.3 \%$ of the interviewees said that at the moment they were interviewed they were talking about politics. Also a very high percentage of the interviewers $85.5 \%$ said that the content of the television programs influences their daily conversations.

The results of this study argument the direct influence of programs with political content on the politicizing of the Kosovar society. These results are supported by theoretical science, while they represent results and they are the first of the kind done about the society in Kosovo. In the meantime, 
the study arguments an overall social perception according to which the Kosovar society is politicized. The connection of the results of the research of the television programming content on the casual conversations of the citizens proves the scientific theories according to which the media define the agenda and the theories which claim that the media do have an effect upon the society, in this case by influencing daily conversations, just as it is argumented in Cohen's scientific theory which claims that the media tell us what to think about, and in the case of this study: what to talk about.

The conclusions of the study are a starting cell he research and study of this subject, which can be developed and produce deeper and wider results with a longer time span. This study can be used in the future by researchers in this field, as a starting point for other studies about the subject - be it for expanding the research or for comparing the results which, in both cases are quite dynamic and might have changed by this time. Be it in the presence of political programs on the studied channels, be it in the percentage of the political conversations influenced by this content. But what will remain unchangeable and will continue to resist the test of time is the fact that the media do have influence on the content of the daily conversations of the citizens, just like in the previous quotes by Bernard Cohen.

\section{References}

1. Cohen Bernard, The Press and the Foreign Policy, Princeton, Princeton University Press, 1963.

2. Katz Elihu, Lazarsfeld Paul, Personal Influence, The Part Played by People in the Flow of Mass Communications, Glencoe, The Free Press, 1955.

3. Lazarsfeld Paul, Berelson Bernard, et Gaudet Hazel, The People's Choice. How the Voter Makes up his Mind in a Presidential Campaign, New York, Duell, Sloan and Pearse 1944 (According to Maigre Erik).

4. Maigre Erik. Sociologjia e komunikimit dhe e mediave. Papirus \& UET Press. Tiranë 2010.

5. McCombs, M. \& Shaw, D. (1972). The Agenda-Setting Function of Mass Media. Public Opinion Quarterly, 36 (Summer), 176-187.

6. RTK (Kosovar Radio television) programming, during 12th, 13th, 14th, 15th, 16th, 17th and 18th of May 2014, from 17:00 to 24:00 hrs. Source media monitoring company PrimeDB.

7. KTV (Koha Vision) programming, during 12th, 13th, 14th, 15th, 16th, 17th and 18th of May 2014, from 17:00 to 24:00 hrs. Source media monitoring company PrimeDB.

8. RTV 21 programming, during 12th, 13th, 14th, 15th, 16th, 17th and 18th of May 2014, from 17:00 to 24:00 hrs. Source media monitoring company PrimeDB.

9. Klan Kosova, programming, during 12th, 13th, 14th, 15th, 16th, 17th and 18th of May 2014, from 17:00 to 24:00 hrs. Source media monitoring company PrimeDB. 